\title{
Óscar Ribas: Escrita e Mediação
}

RITA CHAVES

Universidade de São Paulo

\begin{abstract}
Within the universe of contradictions that defined colonial society, Óscar Ribas's work dynamically articulates the complex relation between intellectual activity and historical process. His career underscores the many impasses faced by authors committed to developing discourse rooted in an understanding of Angola and the formation of a productive imaginary capable of resisting the occlusions and/or the stereotypical vision that characterized colonial literature.
\end{abstract}

Keywords: Angolan literature; colonial literature; national literature; ethnographic narrative.

Do contato com a vasta obra de Óscar Ribas (1909-2004) fica-nos a certeza da sua diversidade tão rica. O mergulho nas águas da tradição oral, o interesse pelos domínios do léxico, a incursão pelos terrenos da religiosidade e da gastronomia (movimentos desdobrados em pesquisa, reflexão e construção de conhecimento), evidenciam uma forma de militância cujo alvo era, de um modo particular, a realidade cultural de sua terra. Essa seria já uma contribuição de Ribas para a compreensão da história de Angola, porém, o seu papel naqueles duros anos da era colonial ensinam-nos mais do que está registrado nas muitas páginas com sua assinatura. Por algumas das pistas que deixou podemos perceber traços de um dilaceramento que é uma espécie de selo do intelectual em tempos de tão acentuada contradição, como não podia deixar de ser a sociedade colonial em que Ribas nasceu, cresceu e se formou.

Como habitante de um tempo cortado por profundas fissuras e assimetrias, ele tem sua trajetória pontuada por um conjunto de dados que traduzem a dinâmica de uma sociedade em movimento, remetendo às crises, aos descompassos, às mudanças que iam ganhando força num período convulsionado. Não podemos esquecer que os anos 50 radicalizam a insatisfação 
e preparam a luta armada pela independência em variados pontos do império lusitano. Eram tempos de grande tensão e a obra de Ribas é também um testemunho dessa época, embora numa trilha diferente daquela que nos marca o olhar quando nos debruçamos sobre a formação da literatura angolana.

Dada a força com que isso se projeta no seu romance Uanga é nele que concentro minha atenção. A análise dessa tão insólita narrativa levanta pontos que permitem apreender a dimensão do intelectual que, de maneira particular, exprime um sentimento de mal-estar - uma espécie de condição do intelectual em tempo de conflitos abertos. Em Uanga, aspectos como a opção pelo gênero literário e o diálogo em dissonância com a literatura colonial oferecem perspectivas para melhor compreender a leitura que se pode fazer do escritor na contemporaneidade.

\section{Um romance em tempo de poesia}

Publicado em 1951, Uanga vem a público em fase de grandes mudanças no cenário angolano. Com fortes injuções internas, o processo de transformação por que ia passando a colônia era também sacudido pela atmosfera internacional. Vivía-se o pós-guerra e o mundo sofria, tanto no domínio político como no território da arte, poderosos abalos. No plano interno, como sabemos, em Angola fermentavam-se as idéias libertadoras que mobilizavam a geração dos Novos Intelectuais, cujas propostas éticas projetaram-se em alguns dos poemas mais significativos da história da sua literatura. Nessa época de glória da poesia, o romance, forma narrativa tão cultuada pelos escritores angolanos, vivia uma fase de retraimento. Recorde-se que o gênero, que já tinha sido cortejado por intelectuais como Félix Machado e Cordeiro da Mata, no século XIX, não obstante o fato de a atividade literária aí ressentir-se da hegemonia do ponto de vista metropolitano, passara por uma etapa de fortalecimento com a produção de Assis Júnior (1887-1960) e Castro Soromenho (1910-1968). A década de 50 contudo foi inundada pelo verbo impetuoso da poesia.

Pode-se, então, dizer que Ribas viria com Uanga quebrar o monopólio do poema, trazendo-nos uma narrativa que procura cumprir algumas das características que definem o romance como gênero. Estou me referindo principalmente à sua capacidade de articular a fantasia ao caráter de documento que esteve na base de sua origem em tantos sistemas literários. Do romance 
britânico do século XVIII ao romance antilhano dos anos 90 do século passado, passando pelo romance brasileiro do século XIX, temos uma linha que aponta para essa mesclagem de compromissos como uma dominante desse gênero de tão difícil definição e tanta capacidade de sobrevivência. Essas duas características certamente explicam a sua importância em fases de afirmação nacional, como podemos vislumbrar no Brasil oitocentista e em meados do século XX em Angola. Sem nunca esquecer a diferença encontrada entre tais contextos, ou seja, um Brasil recém-independente e uma Angola que fazia do sentimento nacional um instrumento para a conquista da independência política, percebemos que o romance sabe funcionar como um repositório onde a vontade de criar se combina com a necessidade de registrar. Essa dupla função ajusta-se muito bem a tempos em que o peso da História se faz sentir de forma tão desabrida.

Escrever um romance quando a tônica era dada pela poesia é já sinal de originalidade. A opção de Ribas pela narrativa não exprime, todavia, apenas um desejo de se diferenciar. Outras motivações certamente conduziam o gesto num contexto sócio-político-cultural em que ganhava peso o compromisso com o sentimento nativista que impunha Angola como tema preferencial. Dessa maneira, Ribas, naquele que seria um exercício estético, investe-se da função do folclorista, papel que desempenharia explicitamente no desenvolvimento de obras como Ilundo (1958) e Izomba (1965). A concepção do colecionismo que orienta a produção de tais livros instala-se em Uanga, como, aliás, já se anuncia no prólogo sugestivamente intitulado "Porquê." Logo nessas duas primeiras páginas, ficamos conhecendo a justificativa para a obra, e, ainda, podemos intuir que a sua publicação sugere certas explicações. Ali estão alguns esclarecimentos: a razão do intervalo entre a produção e a publicação, a natureza da obra, o público a que se destina, e a que ou a quem ela responde. São elementos que ajudam a delinear o contexto, oferecendo-nos pistas também para desvendar a sociedade de que ela é produto.

Sem hesitar, Ribas adverte: a obra lançará o leitor noutra atmosfera psicológica, "num mundo de costumes estranhos, à volta dos quais predomina o feiticismo" (19). Trata-se, ele elucida, de um "documentário da sociedade negra inculta" e não de "um romance de sala." Defendendo-se do impacto que imagina possa ser provocado por seu trabalho, o autor coloca-se na cena cultural, com o cuidado de esclarecer o lugar de onde fala. Assume-se como sujeito de um gesto um tanto solitário, interposto entre o coro que em compasso reclamava o direito 
e o dever de descobrir Angola e aquelas vozes empenhadas na missão de recobrir Angola com véus produzidos sob a perspectiva da metrópole. A ocupação de um lugar intermédio será uma de suas características fundamentais. Em outras palavras, ele buscou, com afinco, o papel de mediador que desempenharia em tantos momentos.

Na quase singularidade desse papel, Ribas constrói os seus textos na linha da expressão auto-etnográfica como a concebe Mary Louise Pratt, para quem autoetnográfico é:

... um texto no qual as pessoas procuram autodescrever-se, tendo em conta as representações que outros fizeram delas. Assim, se os textos etnográficos são aqueles em os sujeitos metropolitanos europeus representam para si mesmos os seus outros (geralmente os seus outros subjugados), os textos auto-etnográficos são representações que os chamados outros constroem em resposta a esses textos ou em diálogo com eles. ("Transculturação" 237)

Importa considerar que nesses casos, o discurso metropolitano é sempre uma referência e a sua presença não deixa de sinalizar a questão da dependência que condiciona o mundo do colonizado. Pratt reitera que a expressão auto-etnográfica não se pode definir pela autenticidade, pois envolve forçosamente uma colaboração com os idiomas da metrópole e tem como alvo os leitores metropolitanos ou os segmentos letrados do grupo social a que pertence o narrador. A auto-etnografia é, sem dúvida, uma expressão dos contextos de fronteira e podem, independentemente da vontade de seus autores, favorecer os processos de transculturação que já apontam para uma relação que se deseja equilibrada. Na possibilidade de intervir na representação metropolitana talvez esteja a marca avançada da dimensão auto-etnográfica que seria cultivado por Ribas. Todavia, a História demonstra que qualquer tentativa de conciliação, por mais honesta que seja, virá sempre limitada pelo traço da dominação, da qual não se consegue escapar fugindo à ruptura.

Da ponta de dilaceramento que se pode depreender em Uanga vemos surgir a figuração de um intelectual que tendo noção da realidade que o cerca, busca, na sua medida, encontrar vias que lhe assegurem esse papel de mediador. Sua incursão na direção contrária a que preconizava a literatura colonial é o caminho que talvez the parecesse possível. Entre o desejo de revelar o universo que o 
discurso colonial não conseguia captar e as concessões que são inerentes à sua situação sócio-cultural, Ribas vai trilhar um percurso revelador do intelectual condicionado por um mundo pautado pela contradição.

Tal contradição projeta-se ainda no campo da recepção da sua obra, pois desde o início sente-se um autor dividido, ou talvez, um autor que ambicione situar-se acima das lacunas que constituiam o seu tempo. É curioso verificar, por exemplo, que se no prólogo se dirige basicamente ao elemento de fora, a dedicatória aponta no sentido da sua identificação com os seus conterrâneos: "A Vós, Irmãos de Angola dedico estas singelas páginas-insignificante fruto tropical colhido nas selvas da Vossa e da Minha Terra" (9). Na base da divisão subjaz a demarcação entre o mundo da afetividade e o universo das relações sociais. Ainda que sem querer, Ribas deixa sinais da "violência atmosférica" tão bem tratada por Fanon em Os condenados da terra (68).

\section{Contra a rotina da literatura colonial}

Clarificada a natureza e a definição de sua obra, Ribas vai mais longe e assinala o seu distanciamento daqueles que, atendendo inclusive aos estímulos do poder, procuravam espalhar a missão civilizadora do Império. Ainda no "Porquê," declara sua posição:

Como desejávamos abeirar-nos da realidade - norma para quem pretende focar uma sociedade - fugimos da rotina seguida pelos escritores coloniais, a quem talvez por ausência de observação, o mundo negro se afigura como uma incógnita. Tal não acontece porque todo problema é solúvel, contanto que se conheça a regra a aplicar. E qual é? Neste caso o conhecimento, não superficial, mas profundo, da matéria versada. Subrdinando-se a este critério, a vida destes povos patenteia-se como a dos outros. Logo, não se envolve de mistério: misterioso é quem, sob os ouropéis da ignorância, a deturpa na sua essência. (20)

Na referência à literatura colonial, revela-se o bom leitor de um repertório que, procurando afirmar-se como um espaço de legitimação da posse da terra, deveria promover o conhecimento de sua realidade. Diferentemente de outros impérios, que buscaram fazer da informação um instrumento de poder, o lusitano destacou- 
se pelo desconhecimento das terras que consideravam ocupadas. A ausência e/ou a fragilidade das instituições vocacionadas para esse fim sintomatizam a incapacidade da metrópole de profissionalizar a sua empresa.

Só mesmo a partir do final dos anos 20, com olhos muito atentos à produtividade da associação pátria/império, o poder que se instala com a ascensão de Salazar procura incentivar uma atividade literária a serviço de seu projeto. Dentro do contexto chamado por Manuel Ferreira de "pirotecnia colonial" (9), em que se integram a criação da Junta de Investigação do Ultramar e da Agência-Geral das Colônias, a organização de grandes exposições e o estabelecimento de programas escolares, tudo a elevar a imagem da grandiosidade do Império, procura-se preencher a lacuna do desconhecimento. Nesse espírito, organizou-se o Concurso de Literatura Colonial, com base numa portaria com objetivos muito nítidos: "intensificar por todos os meios a propaganda das nossas colónias e da obra colonial portuguesa," como está patente no texto do documento oficial que o instituiu (Noa 387).

Embora tenha motivado o desenvolvimento do que se arrola sob a rubrica de literatura colonial, a instituição do Concurso de Literatura Colonial, cuja realização estendeu-se por décadas, na verdade fez surgir textos que mais tematizavam a vida do colono do que o universo do colonizado. Verificamos nesse conjunto de narrativas uma espécie de bloqueio a impedir que a realidade a ser desvendada se convertesse efetivamente em objeto do olhar da maior parte dos narradores. O resultado do esforço daqueles que tentaram atender aos apelos do governo colonial se, por um lado, cumpre a função de cantar a gesta colonial, por outro lado fracassa no objetivo de revelar a colônia, de propiciar o conhecimento sobre os mundos a que tinham chegado (Noa, Império, mito $e$ myopia; Sousa).

Ribas faz questão de assinalar no prólogo de Uanga essa dificuldade de penetrar a realidade da qual deveria tratar. E consegue contrapor-se a esses escritores com um meticuloso trabalho de observação, esforço, aliás, que foi também reconhecido por altas figuras do regime colonial, como Sarmento Rodrigues e Marcelo Caetano. Nas primeiras páginas de vários livros de Ribas, estão registrados testemunhos de tal reconhecimento. Outra prova dessas boas relações encontramos no fato de Uanga ter merecido uma menção honrosa no referido Concurso de Literatura Colonial em 1951. Não obstante essas ligações com ilustres representantes do pensamento colonial, como é o caso de Gastão de 
Sousa Dias e de Amândio César, ele se demarca de todo um grupo que, embora aplicado na função de disseminar o conhecimento sobre a colônia, não conseguia ultrapassar os limites da superficialidade. Para isso com certeza concorrem o seu devotado labor de pesquisa e a sua experiência de vida. Na fatura de seu romance, dois aspectos podem ser vistos como projeções de tal demarcação: a composição das personagens e a constituição do espaço, dados que, sem dúvida, vão incidir na configuração do narrador.

Prevenindo o leitor para a especificidade de seu texto, um "documentário da sociedade negra inculta," Ribas indica, sem vacilar, o mundo sobre o qual focará sua atenção: "o ambientes dos indígenas de Luanda" (19). Está esclarecida a direção de seu projeto, que, segundo o próprio, se não puder satisfazer a necessidade de recreio spiritual (uma das funções da literatura), deverá, ao menos, cumprir a finalidade de dar a conhecer um pouco a vida dos habitantes da cidade de Luanda ainda nas últimas décadas do século XIX. Isso significa que a trama a ser narrada é vivida pelos angolanos que irão desempenhar vivamente o papel de personagens. Ainda que sob um céu de ressalvas que devem remarcar o distanciamento que o autor sente em relação ao seu mundo de origem, esses homens e mulheres irrompem na cena literária, superando os limites da exclusão a que os condenava o narrador colonial.

Assim, em Uanga, não há lugar para a viagem da metrópole à colônia, não há lugar para as motivações daqueles que da sua terra saíam para fazer África, não há lugar para a glorificação das vicissitudes de quem precisa enfrentar esse mundo novo. Falando de mais perto, o autor elabora uma narrativa centrada nas vivências das gentes identificadas com a terra. Catarina, Joaquim, Antonio Sebastião surgem como representantes de um universo cultural que a Ribas interessa apresentar. Ao trazê-los para o centro da narrativa, o escritor coloca-se igualmente no centro da mediação entre os dois mundos que, em linhas gerais, estruturam a sociedade colonial. Observamos aí que salientadas as diferenças, nos variados niveis, inviabiliza-se a idéia de um universo homogêneo, de caráter igualitário que muitas vezes o discurso oficial tentou disseminar. Embora o autor seja muitas vezes associado às propostas luso-tropicalistas, com as quais mantém alguns pontos de identificação, em seu romance a noção de desequilíbrio é mais forte do que a idéia de continuidade que as formulações freirianas defendiam.

Mesmo se focalizados sob uma ótica um tanto exotizante, as personagens afirmam-se, ratificando a sua pertença àquela ordem que interessa focalizar. As 
limitações que ali podemos observar não impedem que, de algum modo, os colonizados recuperem a sua humanidade. Ao regatar o seu papel de sujeito, o narrador atualiza uma proposta apostada na superação de limites de uma literatura que não lhes reservava um lugar que não fosse o de elemento do décor. Tem razão Irene Guerra Marques ao afirmar que:

As personagens são descritas de uma maneira vigorosa e dinâmica. Elas pertencem a um mundo real, agindo e interagindo, cultuando, amando, odiando, num clima de intenso dramatismo. Vão surgindo e dando-se a conhecer através dos diálogos, dos gestos, das ações, como se estivéssemos a assistir a uma sequência cinematográfica. (15)

$\mathrm{Na}$ montagem dessa sequência move-se o narrador, interpondo-se como uma autoridade acerca dos diversos assuntos que se podem associar à trama. Informações sobre práticas rituais como o alembamento, cerimônias de óbito, danças como a massemba, a incorporação de provérbios e advinhas assim como dados de ordem histórica que ajudem a conhecer a cidade e sua gente integram o discurso narrativo. A ficção combina-se verdadeiramente com um esforço documental para dar conta da tarefa que ele se atribui, tarefa afinada com o itinerário do gênero romanesco aqui privilegiado.

Movido pelo desejo de decifrar aquilo que pode parecer misterioso, o autor de Uanga ensaia o papel do etnógrafo, compondo sua narrativa com resultados de um conhecimento acumulado sobre comunidades primitivas. Seguindo a linha do evolucionismo social, a escola da antropologia de grande vigor no século XIX, Ribas manifesta uma visão diacrônica apoiada na noção de avanço, das sociedades mais primitivas para as mais civilizadas. Sem qualquer dúvida a respeito de sua integração entre os segmentos civilizados de uma população heterogênea, encara como sua a tarefa de revelar o passado daquela que também é a sua gente, focalizando as origens da sociedade a que se vê ligado e localizando-as num processo evolutivo. Coerentemente, o conceito de raça, muitas vezes subjacente às elaborações do escritor colonial, é aqui substituído pelo de cultura. Ligam-no ainda a essa corrente antropológica o gosto pelo trabalho de gabinete e a tendência para o jogo comparativo, vislumbrando pontos de contato que façam prever um futuro para esses setores ainda não tocados pelo sentidos da modernidade: 
Tal como nas mitologias dos países antigos, hoje na florescência da civilização, as grandes e pequenas divindades também figuram com nomes diferentes, quer de povo para povo, quer de tribo para tribo. Primeiramente seres humanos habitam a atmosfera da Terra, onde conservam os hábitos, e, em virtude da multiplicidade de práticas, dominam-nos de todas as maneiras. (Ribas 36)

Mais próximo do que hoje a antropologia reconhece como folclorista, Ribas traz para a escrita romanesca a tendência para o colecionismo que exercitou francamente em trabalhos de recolha. Aqui, articulando-se ao desenrolar da trama, inscrevem-se na narrativa os dados minuciosamente recolhidos, seja através da consulta a livros, seja através da consulta a informantes que ele pôde encontrar, inclusive, em sua própria família. Pelo roteiro seguido, ele aproximase da concepção de antiquário, um tipo de intelectual que floresceu na Inglaterra do século XIX, desenvolvendo uma tendência que tem sua origem no século XVI (Gomes). A caracterizá-lo temos a ligação com uma gama variada de assuntos como festas, crenças, práticas religiosas, formas associativas, etc, marca complementada pelo "amor às antiguidades." Em Ribas, encontramos as duas características, entretanto se a primeira é indiscutível, no caso da segunda temos uma carga de ambiguidade que atesta a personalidade pouco comum do nosso intelectual.

Uanga inicia-se com uma remissão ao passado. O primeiro capítulo chamase "Antigamente . . ." e a expressão evoca o "era uma vez," forma introdutória de estórias situadas em tempos imemoriais, impressão que se corrige com a indicação precisa do ano de 1882, como o tempo que abriga os fatos que serão contados. Pode-se dizer que o etnógrafo complementa-se com o historiador, reiterando o senso de historicidade que é próprio do romance. O sentido de precisão integra-se aos marcos da verossimilhança a que o autor faz menção no prólogo. E ali explica que dado o interesse de recuperar práticas já extintas pela civilização, enquadrou sua estória num tempo remoto. Recorrendo àqueles que ele identifica como os "indígenas," Ribas fica à vontade para discorrer sobre um modo de vida que a modernização da cidade teria interditado.

Além da opção por personagens enraizados na terra, outro elemento distinguirá Uanga da linha predominante no romance colonial. Trata-se da 
composição do espaço em que se desenrolará a trama. A relevância do espaço como elemento estrutural no repertório colonial é tão expressiva que podemos notar a frequência de sua presença nos títulos das obras. Explícito ou não, o topônimo África é uma constante e aparece muitas e muitas vezes cercado por uma atmosfera de mistério e grandiosidade, como se pode notar, por exemplo, em dezenas de títulos publicados principalmente entre os anos 40 e 60.

$\mathrm{O}$ aspecto enigmático e, ao mesmo tempo, sedutor da terra a ser desbravada é frequentemente enfatizado. Em sua imensa maioria, os narradores da literatura colonial expressam a sensação de se sentirem diante de um "novo mundo" e radicalizando a experiência do exotismo vão centrar suas histórias fora das cidades. Sobre tal fato, argumenta Francisco Noa, um dos poucos e bons conhecedores desse repertório:

Um dos aspectos que torna particularmente expressiva a representação do exótico é a localização das próprias histórias que se desenvolvem dominantemente no mato. Aliás, há uma relação metonímica entre África e o mato e que será explorada até à exaustão na literatura colonial. . . . (64)

Um dos aspectos que torna particularmente expressiva a representação do exótico é a localização das próprias histórias que se desenvolvem dominantemente no mato. Aliás, há uma relação metonímica entre África e o mato e que será explorada até à exaustão na literatura colonial, validando as colocações de Bernard Mouralis acerca do discurso exótico e a construção de uma estética particular que ele encerra:

O discurso exótico ordena-se assim Segundo uma retórica que visa a expressão e a caracterização de uma realidade considerada como fundamentalmente diferente. Trata-se em primeiro lugar, de uma retórica que pretende fazer ver - e sentir - essa realidade que é, muitas vezes, necessário explicar ou 'traduzir"ao leitor. (95)

O olhar de Ribas quebra essa relação metonímica ao incorporar a cidade e seus arredores, centrando sua atenção no patrimônio cultural dos habitantes. A cidade deixa de ser apenas um cenário, transformando-se num lugar de cultura, em cujas ruas se forma e se transforma um conjunto de crenças, práticas, hábitos, ou seja, 
um modo de estar que reflete uma dinâmica histórica e socialmente constituída. Esse movimento faz com que as personagens ganhem força, reconquistem simbolicamente a humanidade que o processo reificador do colonialismo interdita.

\section{A presença do tempo e a consciência do narrador}

Pelas frequentes remissões, percebemos que o espaço se conjuga com o tempo, situando-se, portanto, nas linhas da História. Supera-se, desse modo, o estatuto de natureza, limite que a literatura colonial procura instituir para os territórios africanos. Também não se defende no texto a valorização de qualquer crença na essencialidade africana ou angolana. Ali, o narrador tece comparações com o passado e faz prospecções para o futuro, recusando o peso de atitudes puramente nostálgicas. Em síntese, podemos dizer que, cioso da legitimidade da função de recordar o passado, Ribas não deixa de saudar a chegada do futuro, louvando os benefícios desse período de luzes que, em sua opinião, vem assegurar dignidade à cidade de Luanda: "Após longa infância, a Luanda de feras, de quifumbes, de vegetação bravia, compreendeu que devia ganhar personalidade para merecer condignamente o respeitável título de capital" (26-27).

Por "personalidade" temos que entender o aparato da modernidade urbana, quer dizer, a conquista de tudo que a distancie da mata, da floresta, da noção mais convencional de perigo para o dito civilizado da época. Ribas, nesse aspecto, ratifica a diferença em relação ao que se via como o protótipo do homem africano, marcado por uma comunhão com a natureza, cujo reconhecimento era, acima de tudo, uma maneira de negar a sua capacidade de produzir cultura. Curioso, entretanto, é o alerta ecológico que a narrativa de Ribas traz, chamando a atenção para o absurdo do desmatamento, numa atitude antecipatória do que seriam as preocupações já do fim do século XX:

Ó formosa Luanda, não desprezes as belezas naturais. Nasceste na selva, entre verdura e madrigais, portanto és irmã das terras do sertão. Se queres semelhar um diadema de pedrarias sonoras, retoma as fartas rouparias arborescentes, impregna ovamente o espaço de celestes melodias. Enfim, faz de cada árvore um palco, de cada pássaro um cantor teu. Reverdece-te, pois, sê uma eterna canção. Cultivando a árvore, atraindo, como outrora, as 
grandes famílias de rolas, maracachões, bicos de lacre, bicos de prata. Viuvinhas, rabos de junco, celestes, bigodes e outras mais, teu casario, esmaltado de verde, afagado virginalmene, ganhará mais frescura, mais encanto. Enfeitiça seus filhos, enfeitiça o viandante. Não te envergonhes de enfeitiçar: o feitiço é o imã da beleza. Se assim fizeres, dominarás como rainha. Mas repara: não consintas que profanem teu esplendor. Combate as fisgas e as caçadeiras - regras dos grandes países. (27-28)

Há, pois, aí um jogo de concepções que torna no mínimo curioso o espírito que preside o romance, balizado por essa interessante dualidade: a defesa do meioambiente coexistindo com um certo conservadorismo diante do universo cultural que procura descrever. A longa citação permite ainda verificar a familiaridade com o meio, articulada com o espírito enciclopédico do escritor. A enumeração exaustiva dos nomes dos pássaros demonstra esse conhecimento que parece uma mescla de experiência e informação e aponta para o caráter especial desse narrador que faz questão de revelar a consciência de seu próprio récit.

É precisamente na constituição desse narrador, algo inquieto, intrometido, que se recusa a conter a sua emoção diante do que narra que podemos encontrar traços do intelectual um tanto dilacerado que, sob vários aspectos, podemos ver em Ribas. No processo de estruturação da narativa, temos um narrador inconstante, que se na maior parte do tempo ancora o seu discurso na pesquisa, reforçando a noção de distância que o separa do universo focalizado, em alguns momentos, mais do que o interesse que a própria escrita do romance atesta (para além do restante de sua obra), vamos encontrar pontas de uma adesão a esse mundo que ele apresenta como da "sociedade negra inculta." A forma de referir algumas personagens como "Tio João" e "mamãe" exprime a redução da distância, assim como no domínio da linguagem o recurso ao discurso indireto livre sintomatiza a contaminação que envolve o narrador.

Nesse óbvio movimento de hesitante aproximação com o universo do qual ao mesmo tempo ele se demarca, é que podemos examinar com maior nitidez a trajetória de Ribas, isto é, para compreender seu itinerário, é preciso não perder de vista a sua condição numa sociedade calcada na mesclagem e na discriminação a um só tempo. Assim se pode ler a heterogeneidade de seu texto que carrega outra característica da auto-etnografia, que é constituir um "ponto de entrada de um grupo na cultura letrada metropolitana" (Pratt, Os olhos do império 34). 


\section{Entre o esclarecimento e a conciliação: o intelectual}

Não obstante o traço da concessão que se levanta em vários momentos de sua escrita, assinalando a dimensão evolucionista da sua abordagem, Ribas, um tanto a contrapelo, oferece elementos para um conhecimento de Angola. Sem deixar de levar em conta a diferença em relação ao comportamento ousado dos intelectuais que fizeram ecoar o grito de "Vamos descobrir Angola," e certamente inclusive pelo êxito que eles conquistaram na defesa da ruptura, é possível e desejável que se leia Uanga também considerando os aspectos que o confrontam com a literatura colonial. Examinando-o em diálogo com o contexto de formação do escritor e com a situação de isolamento que ele experimentava, podemos melhor captar os matizes de um projeto pautado pela ambivalência, perigo inerente às propostas de mediação em sociedades constituídas sobre abismos. Assim era a sociedade colonial na qual Ribas pretendeu construir pontes. Olhando a verticalidade das fissuras que definiam aqueles anos em que a ruptura se prenunciava, melhor enxergamos a tentação do papel cobiçado, mas também melhor se pode recuperar a feição mais avançada da obra.

$\mathrm{Na}$ leitura de conjunto que o legado de Ribas reclama, não se pode ficar alheio ao seu compromisso com aquilo que ele considerava um projeto para a sua terra. Assim se pode compreender o seu trabalho, dono de uma diversidade que refletia um espírito inquieto, desejoso de construir uma obra que desse conta de uma realidade ainda tão desconhecida pelas diferentes camadas que compunham a sociedade em que estavam necessariamente inseridas. E é a partir desse lugar, das franjas de uma sociedade pautada pela divisão, cortada pelas linhas da segregação em várias dimensões, que Ribas pôde falar. A análise de seu percurso intelectual, no compasso dos avanços e dos recuos que aquele contexto sóciocultural condicionava, é fundamental para a compreensão da complexidade de décadas tão significativas na constituição do país que a atividade literária ajudava a inventar.

Em síntese, a trajetória do homem, do escritor, do intelectual pode e deve ser vista por ângulos que apurem a percepção do universo colonial, sua força, sua maneira de gerar condicionalismos. Com tanta complexidade o escritor procurou lidar, avançando sob alguns aspectos, recuando noutras perspectivas, mas impondo sempre a sua presença à chamada cena histórica de que fez parte. 


\section{Obras Citadas}

Chaves, Rita. A formação do romance angolano. São Paulo/Maputo: Via Atlântica/FBLP, 1999. Impresso.

Marques, Irene Guerra. "Prefácio.” Uanga de Óscar Ribas. Luanda: União dos Escritores Angolanos, 1985. Impresso.

Mouralis, Bernard. As contra-literaturas. Coimbra: Almedina, 1982. Impresso.

Neves, Alexandre Gomes. "Câmara Cascudo e Óscar Ribas: Diálogos no Atlântico.” Dissertação de Mestrado. U de São Paulo, 2008. Impresso.

Noa, Francisco. Império, mito e miopia-Moçambique como invenção literária. São Paulo: Kapulana, 2015.

—."Literatura colonial em moçambique: o paradigma submerso." Via Atlântica (1999): 59-68. Impresso.

Pratt, Mary Louise. Os olhos do império: Relatos de viagem e tranculturação. Bauru (Brasil): Edusc, 1999. Impresso.

—. "Transculturação e auto-etnografia: Peru 1615/1980." Deslocalizar a Europa. Ed. Manuela Ribeiro Sanches. Lisboa: Cotovia, 2005. Impresso.

Ribas, Óscar. Uanga. Luanda: União dos Escritores Angolanos, 1985. Impresso. Sousa, Sandra. Ficções do Outro: Império, Raça e Subjectividade no Moçambique Colonial. Lisboa: CLEPUL, 2014. Impresso.

Lopes, Angela Leite. Nelson Rodrigues: Trágico, então Moderno. Rio de Janeiro: U Federal do Rio de Janeiro, 1993. Print.

Magaldi, Sábato. Nelson Rodrigues: Dramaturgia e encenações. São Paulo: Perspectiva, 1987. Print.

Mannoni, Octave. Clefs Pour l'Imaginaire. Paris: Seuil, 1969. Print.

Marx, Carl. Capital. London: Lawrence and Wishart, 2003. Print.

Pietz, William. "The Problem of the Fetish, II: The Origin of the Fetish." RES 13 (1987): 23-45. Print.

Rodrigues, Nelson, and Sábato Magaldi. Teatro completo. Rio de Janeiro: Nova Aguilar, 2003. Print.

Schor, Naomi. "Female Fetishism: The Case of George Sand." Poetics Today 6.1-2 (1985): 301-10. Print. 